\title{
Democracia y deliberación pública desde la perspectiva rawlsiana*
}

\author{
M. ${ }^{a}$ PILAR GONZÁLEZ ALTABLE \\ Universidad de Valencia
}

RESUMEN. En el presente trabajo me centro, principalmente, en una de las cuestiones que ocupan, a mi modo de ver, el primer plano de la reflexión teórica actual: el problema de la democracia como forma política del uso público de la razón por parte de todos, estudiándolo desde el paradigma que nos ofrece John Rawls en sus últimas obras. Sobre todo en el papel y límite que Rawls asigna a la «Razón pública» y la «Deliberación pública», cuyo análisis me parece enormemente sugerente e iluminador para la Teoría democrática contemporánea.

He analizado, en primer lugar, la relación entre democracia y concepción política de justicia, y en segundo, la razón pública y los límites de la deliberación pública. Concluyendo que la concepción presentada de la razón pública está comprometida, sobre todo, con delimitar un espacio que no puede estar sometido a intereses, ya sean estratégicos o incluso deliberativos, porque está garantizado por la concepción política de justicia, aceptada por todos. Una concepción que intenta superar el conflicto entre formas de vida diferentes a través del ideal de justicia y los derechos.
ABSTRACT. In this paper we shall center in one of the questions that takes up the first plan of the nowadays theoretical reflexion: the problem of democracy as the political form of the public use of reason. We shall take it from the paradigm that presents J. Rawls in his last works with a view specially to the function and limits that Rawls asigns to «public Reason» and «public Deliberation». The analysis of these concepts seems to me hugely illuminating for the contemporary democratic theory.

In the first place I have analysed the relation between democracy and political conception of justice, and afterwards between public reason and the limits of public deliberation. I conclude that the displayed conception of public reason mainly aspires to mark the boundaries of a space that cannot be subjected to interests, either strategical or even deliberative, because it is secured by a political conception of justice which is acepted by everyone. A conception that tries to overcome the conflict between different forms of life through the ideal of justice and human rights.

* Este trabajo se ha realizado en el marco del Proyecto de Investigación (GV00-158-08) y una primera redacción del mismo se presentó en el Seminario sobre «El modelo democrático liberal ante los desafíos contemporáneos», celebrado en la Universidad de Valencia. 


\section{Introducción}

Es indudable que John Rawls ha sido una de las figuras más relevantes de este siglo en el campo de la Teoría política y la Filosofía del Derecho del siglo XX. Su pensamiento ha sido un punto de referencia obligado para todos aquellos que se ocupan de cuestiones morales, políticas y económicas, y en general de problemas de legitimación y justicia (M. ${ }^{a}$ P. González Altable, 1993, p. 15). El pensamiento global de Rawls supone desde sus inicios un avance de la filosofía liberal, moral y política, incorporando el problema de la justicia social como un tema clave de su reflexión y análisis.

Rawls es el ejemplo de un pensamiento dinámico y en continua adaptación, pues desde la publicación de su Theory of Justice en 1971 hasta sus últimas producciones - Political Liberalism, The Law of People, Justice as Fairness: A Restatement - ha tratado de proporcionar un cuerpo teórico capaz de fundamentar unos principios de justicia para una sociedad democrática liberal, cuya característica fundamental es la existencia de un pluralismo de doctrinas morales, filosóficas y religiosas distintas.

Por tanto, el objetivo central de la obra de Rawls es proporcionar una concepción política de justicia que proporcione legitimidad a la democracia constitucional propia de nuestras sociedades contemporáneas. Objetivo que se vislumbra sobre todo de una forma explícita a partir de su obra Liberalismo Político.

Aunque hay acuerdo en que Teoría de la Justicia es una teoría más sustantiva que el Liberalismo Político, creo que lo que hace precisamente Rawls en sus últimos escritos es una muestra de la apertura y dinamismo de la teoría, pues desarrolla las ideas que ya estaban en ella, explicitando claramente que la concepción política de justicia tiene un objetivo práctico, proporcionar legitimidad a la estructura normativa de una sociedad plural, a través del régimen constitucional democrático que marca los límites dentro de los cuales la deliberación pública sobre decisiones públicas se realiza por parte de los ciudadanos de forma que el ideal democrático se pueda realizar en nuestras sociedades democráticas.

La necesidad de toda esta reflexión sobre los fundamentos, desde dentro del propio proyecto de la modernidad, se hizo necesaria sobre todo por los desafíos, y por los problemas a los que la teoría moral y política tenía que hacer frente, como la necesidad de buscar un punto de acuerdo sobre el fundamento de la asociación política; el problema del orden social y de los principios que deben regular la vida política que se subsumen dentro de los requerimientos de la legitimidad racional moderna: «sólo son legítimos aquellos principios que puedan ser racionalmente aceptados por todos los ciudadanos a los que han de vincular» (F. Vallespín, 1998, p. 11); el problema del reconocimiento de la pluralidad de concepciones morales, religiosas, 
filosóficas y de formas de vida distintas, como una característica esencial de nuestras sociedades. Lo cual ha supuesto, sin duda, la necesidad de una reflexión profunda sobre la realización de los ideales y valores democráticos y de una evolución del propio modelo democrático liberal si se quería dar respuesta a dichos problemas y desafíos.

Como señala Sebreli (1992), el espíritu del tiempo intelectual de las últimas décadas se ha caracterizado por el abandono en la sociedad occidental de todo lo que significaron sus rasgos distintivos: el racionalismo, la creencia en la ciencia y la técnica, la idea de progreso y modernidad y que en general se ha englobado bajo la noción de postmodernismo. Es éste el momento en el que a la concepción objetivista de los valores se opuso el relativismo, y al universalismo, los particularismo culturales. Pero pronto estos mismos particularismos se han mostrado insuficientes para dar respuesta a los múltiples problemas que plantean las sociedades contemporáneas ${ }^{1}$.

Como plantea A. Gutmann (1993), hoy las sociedades se enfrentan al desafío puesto por el multiculturalismo a la justicia social, a la posibilidad de justificar unos estándares de justicia universalmente aceptables que permitan la cooperación y el desarrollo democrático de las sociedades. O mejor dicho, la posibilidad de una concepción política de justicia pública, como conjunto de principios normativos abstractos y de un cierto carácter universal.

Por ello, el problema que se genera al intentar liberarse del relativismo está en saber si es posible una ética objetiva, universal e imparcial. Los valores morales no son conocimientos empíricos y demostrables, las normas éticas no son leyes científicas generales establecidas y verificables, sino que implican un determinado significado de la existencia humana y, por lo tanto, pertenecen al campo del conocimiento filosófico y no científico (Sebreli, 1992, p. 73).

El problema central está en encontrar una estructura normativa universal, que garantice poder defender ideas básicas, como los derechos humanos, la libertad, la igualdad, la justicia social, para las sociedades en su globalidad, cuando éstas no forman un todo uniforme sino más bien diferenciado y distinto.

Aunque hoy se admite de forma generalizada que la democracia liberal ha triunfado, es un hecho que las sociedades liberales occidentales están acosadas por una multitud de problemas sociales cuyo curso, de acuerdo con muchos críticos, tanto desde dentro como desde fuera del pensamiento liberal, se vincula en última instancia a una cultura del individualismo y a una descomposición de los valores comunes de la que el pensamiento liberal por sí mismo es responsable (S. Sheffler, 1994).

Es evidente que mientras la tendencia de esta crítica se encamina a afirmar la necesidad de una mayor unidad y cohesión social, la idea de una sociedad liberal como una única comunidad nacional con una cultura común

1 Sobre este punto veánse los análisis de Sebreli (1992), A. Gutmann (1993) y Sartori (2001). 
está también bajo ataque, pues el incremento de poblaciones diversificadas trae conflictos con sus propias historias de exclusión y acomodación de las demandas del multiculturalismo y del pluralismo cultural.

Hoy nos encontramos con que las sociedades democráticas y los regímenes democráticos tienen que hacer frente al desafío que la pluralidad cultural plantea y a la posibilidad de justificar unos estándares de justicia universalmente aceptables que permitan la cooperación y el desarrollo democrático de las sociedades.

Es un hecho que una concepción democrática de la sociedad no postula la unidad, sino que, por el contrario, acepta la división, las contradicciones, la pluralidad, pero la división no es absoluta, hay un terreno común: la aceptación concertada de las reglas del juego democrático, la posibilidad de discusión, la tolerancia a través del discurso y la aceptación de unos valores básicos como «libertad», «igualdad», «individualidad», «derechos» y la posibilidad de unos estandares de justicia social compartida.

Ello ha llevado a la mayoría de los teóricos y científicos de la política a tratar de aclarar, como nos señala Rafael del Águila (1995), algo que cada vez nos parece más confuso: «el significado de la democracia».

Cuando hablamos de democracia liberal estamos tratando, sin ninguna duda, no sólo con posiciones políticas ambiguas, sino también con problemas de identidad política. En ambas posiciones hay conceptos como el de autonomía, libertad e igualdad que el teórico tiene que equilibrar, pues, como señala A. Touraine,

... la democracia es un equilibrio siempre inestable entre libertad e igualdad ${ }^{2}$.

Por eso quizás la metáfora utilizada por Rafael del Águila para definir la democracia liberal como el centauro transmoderno, cuya condición de centauro nos advierte contra soluciones simplificadoras que intentan ir «más allá» de su carácter irremediablemente escindido, sea un fiel reflejo del panorama contemporáneo, pues

... Quizás, después de todo, la democracia liberal sea eso, y resulte tonto pretenderla otra cosa. Quizá lo definidor de nuestra condición política actual sea, precisamente, la necesidad de elegir en un mundo en el que la escisión, la pluralidad y la contingencia dotan a nuestras acciones de una estructura trágica. [...] Quizás por eso el centauro transmoderno, por muy sabio que a la postre resulte, no pueda nunca dejar de ser un centauro. [...] debería asumir antes de nada la esencial duplicidad de todo, incluyendo su propia personalidad (Rafael del Águila, 1995, p. 641).

De todas formas, como señala Elías Díaz (2002, p. 45), tanto por razones de eficacia (cohesión social, comunidad cívica) y, unidas a ellas, por razones

${ }^{2}$ Alain Touraine (1995, p. 23) véase también A. Touraine (1994). 
éticas (valores de libertad, igualdad y solidaridad) la «propuesta normativa de nuestro tiempo debe ser la universalización de la democracia. No hay futuro para nadie si no se avanza en ella, en la universalización de los derechos humanos, en su protección y realización efectiva en esa escala».

En este contexto dos cuestiones ocupan el primer plano de la reflexión teórica actual: por un lado, tratar de dar respuesta al problema de la diferencia y del pluralismo cultural, como un momento de la complejidad propia de las sociedades contemporáneas, al que hay que darle una forma jurídica para garantizar, antes que nada, su misma existencia en contextos crecientemente complejos de interacción; siendo al mismo tiempo respetuosas con la libertad, la autonomía y los derechos de los sujetos ${ }^{3}$. Por otro, el de la democracia como forma política del uso público de la razón por parte de todos.

En el presente trabajo me voy a centrar principalmente en el segundo de los problemas planteados, tratando de abordarle desde la perspectiva o el paradigma que nos ofrece John Rawls en sus últimas obras (Political Liberalism, The Law of Peoples y Justice as Fairness: A Restatement), sobre todo en el papel y límite que Rawls asigna a la «Razón pública» y la «Deliberación pública», cuyo análisis me parece enormemente sugerente e iluminador para la Teoría democrática contemporánea.

Parece que hay un cierto consenso en concebir a la democracia, entre otras cosas, como una forma racionalmente eficaz de garantizar, en la práctica, a los individuos un derecho igual a tomar parte en la producción de bienes públicos y en la promoción de sus intereses comunes al cooperar en su ejecución.

La democracia es, pues, un conjunto de procedimientos para tomar decisiones públicas que afectan a la sociedad en su globalidad, con arreglo a ciertos principios, valores y restricciones.

En este contexto es ineludible la tensión entre libertad y democracia, entre los valores que protegen la libertad individual y los que respetan la voluntad de la mayoría, entre el principio de legitimidad liberal y el principio democrático.

Una aproximación a la posibilidad de superar esa tensión la encontramos en el Liberalismo Político de Rawls, donde el principio de libertad e igualdad, junto con otros valores, se ajustan en un espacio de deliberación pública restringido por la razón pública, que es expresión de la concepción política de justicia, la cual es el núcleo de un consenso superpuesto entre todos los individuos que comparten formas de vida diferentes.

El punto de partida de Rawls es tratar de proporcionar una concepción de justicia que posibilite considerar bien ordenados a los regímenes democráticos, propios de las sociedades democráticas liberales occidentales.

Ello hace que desde el principio esté comprometido con la justificación de una concepción política de justicia que sirva de base legitimadora de la

\footnotetext{
${ }^{3}$ Carlos Thiebaut (1994); véase también, Javier de Lucas (1994a y 1994b); J. Habermas (1994); A. Gutmann (1995 y 1994).
} 
democracia liberal. Pues el sistema de normas tiene un lugar central en la vida pública del grupo. Los miembros del grupo se valoran mutuamente las actividades y los propósitos en términos de un sistema de normas. Éste les proporciona las razones a favor o en contra de las acciones y fines de los miembros, cualquiera que sean sus intereses y deseos. Así, por ejemplo, nos vamos a encontrar que en el debate político, el hecho de que una ley concreta viole los derechos constitucionales de los individuos, cree desempleo o incremente la pobreza constituye lo que podemos denominar razones públicas en contra de esa ley ${ }^{4}$.

El rol público de la razón nos capacita para justificarnos unos a otros nuestra conducta y explicarnos nuestra elección de fines, de acuerdo a normas que son básicas para la existencia del grupo social.

Es un hecho constatable que en el presente todavía no se ha conseguido lograr un acuerdo de validez universal sobre la forma en que las instituciones de una democracia constitucional deberían ser configuradas, si tuvieran que satisfacer los términos equitativos de cooperación entre ciudadanos vistos como libres e iguales.

\section{Democracia y concepción política de justicia}

Este desacuerdo para Rawls ejemplifica el conflicto existente entre dos tradiciones dentro del pensamiento democrático mismo. Por un lado, la tradición asociada a Locke y, por otro, la tradición asociada a Rousseau.

Justicia como equidad, en este contexto, intenta ser juez entre esas dos tradiciones y responder a la siguiente cuestión:

¿Cómo es posible la existencia de una sociedad justa y estable formada a su vez por ciudadanos libres e iguales que todavía se mantienen profundamente divididos por doctrinas morales, religiosas y filosóficas comprehensivas razonables? O dicho de otra forma: ¿cómo es posible que doctrinas comprehensivas profundamente opuestas y pensadas como razonables puedan convivir y afirmar la concepción política de un régimen constitucional? ${ }^{5}$.

${ }_{4}^{4}$ Véase sobre este punto Samuel Freeman (1990).

${ }^{5}$ John Rawls (1993, p. xviii); véase también J. Rawls (1972, 1987,1989 y 1995).

Rawls reformula esta cuestión en la introducción a la edición en paperback del Liberalismo Político (1996, pp. xxxix-xl) señalando: «... ¿Cómo es posible para aquéllos afirmar una doctrina religiosa basada en la autoridad religiosa, por ejemplo, la Iglesia o la Biblia, y al mismo tiempo mantener una concepción política razonable que suporte un régimen democrático justo?

El punto es que no todas las doctrinas comprensivas razonables son doctrinas comprensivas liberales; así la cuestión es si pueden todavía ser compatibles, en base a razones correctas (right reasons), con una concepción política liberal. Para lograr esto, entiendo, no es suficiente que esas doctrinas acepten un régimen democrático meramente como un modus vivendi. Más bien deben aceptarlo como miembros de un razonable consenso superpuesto (reasonable overlapping consensus) 》 (la traducción es mía). 
Lo esencial de la respuesta rawlsiana está en que para que semejante sociedad sea posible, su estructura básica debe estar efectivamente regulada por una concepción política de justicia - justicia como equidad- que sea el centro de un consenso superpuesto (overlapping consensus) al menos de doctrinas comprenhensivas razonablemente afirmadas por sus ciudadanos.

En este sentido la intención de justicia como equidad es práctica. Justicia como equidad se presenta a sí misma no como una concepción de justicia verdadera, lo que dificultaría, sin ninguna duda, ser el centro de un consenso, sino como una concepción de justicia que pretende servir como base de un acuerdo político voluntario e informado. Su intención práctica es, por tanto, proporcionar las bases de justificación pública del acuerdo constitucional en una democracia.

Mas para alcanzar semejante razón compartida, la concepción de justicia debería ser, tanto como sea posible, independiente de doctrinas religiosas, morales y filosóficas opuestas y a veces encontradas.

De ahí que el liberalismo político intente partir de una concepción política de justicia free-standing, capaz de ganar el soporte de un consenso superpuesto de la pluralidad de doctrinas y visiones del mundo existentes en una sociedad regulada por ella, garantizando así su estabilidad.

Justicia como equidad, como una concepción free-standing, es una concepción moral que trabaja para un objeto específico: la estructura básica de la sociedad de un régimen constitucional democrático.

Es una doctrina que se explica y justifica al margen de, o sin referencia a, un fundamento más extenso en base a doctrinas comprehensivas, sean del tipo que sean.

Es una concepción de justicia formulada en términos de ciertas ideas intuitivas insertas en la cultura política de una sociedad democrática.

Todo ello la hace, en opinión de Rawls, candidata para ser el centro de un consenso superpuesto de doctrinas morales, religiosas y filosóficas razonables pero distintas y que no tienen por qué ser liberales.

No podemos olvidar que el problema central para Rawls $(1996, \mathrm{p} . \mathrm{xl})$ es proporcionar una concepción política de justicia para un régimen constitucional democrático a la que una pluralidad de doctrinas razonables, religiosas y no religiosas, liberales y no liberales, puedan libremente suscribir y así vivir libremente, a través de una comprensión de sus virtudes y de una aceptación en base a razones correctas.

Cuando los ciudadanos comparten principios de justicia razonables tienen las bases sobre las que la discusión de las cuestiones políticas fundamentales pueden proceder y ser razonablemente decididas, no naturalmente en todos los casos, pero sí en la mayoría.

De esta forma, el dualismo que encontramos en el liberalismo político rawlsiano, entre el punto de vista que supone la concepción política de justi- 
cia y el de la pluralidad de doctrinas es un dualismo que se origina en la naturaleza especial de la cultura política democrática como marcada por un pluralismo razonable.

Pluralismo que no es meramente una condición histórica efímera, sino una característica permanente de la cultura pública de una democracia.

Aunque las doctrinas históricas no sean, naturalmente, el trabajo de la razón libre sola, el hecho del pluralismo razonable no es una condición desafortunada de la vida humana.

En este sentido, cuando Rawls trata de lograr que la concepción política de justicia gane el soporte de doctrinas distintas, no se está ajustando a la concepción de la fuerza bruta del mundo, sino al resultado inevitable de la razón humana libre.

Esta cultura pública comprende las instituciones políticas de un régimen constitucional y las tradiciones públicas de su interpretación. Por el contrario, las doctrinas comprehensivas del tipo que sean (liberales o no liberales, religiosas o no religiosas, etc.) pertenecen a lo que podemos llamar la cultura underground de la sociedad civil.

La cultura underground es la cultura de lo social y no de lo político. Es la cultura de la vida diaria, de sus asociaciones principales: iglesias, universidades, sociedades científicas, clubes, etc.

Por ello, en este punto, para Rawls es esencial que podamos, con perfecta consistencia, mantener que sería irrazonable usar el poder político para reforzar nuestra propia visión comprehensiva, aunque consideremos y mantengamos que es razonable o verdadera (J. Rawls, 1993, p. 138).

Pues el punto central no es el de conseguir que aquellos que rechacen una concepción determinada la acepten, o actúen de acuerdo con ella por sanciones factibles, como si la tarea fuera encontrar formas de imponer esa concepción una vez que estemos convencidos de su solidez, sino de aplicar el principio de tolerancia democrática ${ }^{6}$.

Para ello es necesario contar con una concepción de justicia, que al ser el núcleo de un consenso superpuesto, garantice la estabilidad al proporcionar los principios de justicia que abarquen toda la estructura básica social y sean presumidos en la etapa constitucional.

Justicia como equidad, en la medida que es núcleo del consenso superpuesto, trabaja, de esta forma, desde las ideas fundamentales de la sociedad como un sistema equitativo de cooperación junto con la concepción de la persona como libre e igual. Esas ideas son tomadas como centrales para el ideal democrático.

La concepción política, objeto de ese consenso, es entonces afirmada como una concepción moral y los ciudadanos están libres para actuar desde ella sobre fundamentos morales.

\footnotetext{
' Pero teniendo en cuenta que la «tolerancia liberal [...] está lejos de la idea del todo vale» (J. Gray, 2001, p. 30).
} 
La aceptación de dicha concepción no es, por tanto, un mero compromiso entre quienes mantienen visiones diferentes, sino que descansa más bien en la totalidad de razones especificadas dentro de la doctrina comprehensiva que es afirmada por cada uno de los que subscribe el consenso superpuesto.

Semejante consenso alcanza la sumisión por un ajuste concordante entre la concepción política y las visiones comprehensivas, junto con el reconocimiento público de los valores esenciales de las virtudes políticas.

En este sentido el liberalismo político no es escéptico ni indiferente con respecto a la verdad religiosa, moral o filosófica, sino más bien asume la limitación humana para llegar a ella y trata de encontrar aquello que nos une, en lugar de lo que nos separa, para lograr un orden constitucional justo en base a la razonabilidad y justificar un régimen constitucional bien ordenado.

Puesto que no hay certeza de quién posee la verdad es preciso admitir la confrontación de ideas opuestas, la discusión, la tolerancia a través del discurso sobre una estructura normativa común que garantice la unidad y estabilidad social de forma que la sociedad sea un sistema equitativo de cooperación y sea posible la coexistencia de formas de vida diferentes con derechos iguales.

Ello significa poder asegurar a cada ciudadano la oportunidad de crear su propia identidad a partir de todo lo que recibe sin necesidad de renunciar a su herencia cultural (A. Gutmann, 1995), y sin necesidad tampoco de introducir una clase de derechos colectivos para salvaguardar su derecho a la diferencia, que supondría, como señala Habermas,

... una exigencia demasiado fuerte para una teoría de los derechos confeccionada para personas individuales (J. Habermas, 1994, p. 130).

En esas circunstancias, un sopesar las razones desde dentro de la doctrina comprehensiva por parte de cada ciudadano en el ámbito de la sociedad civil es la base para alcanzar un consenso superpuesto sobre una concepción política de justicia y aceptar los límites de la razón pública.

\section{Razón pública y los límites de la deliberación pública}

En este punto se hace necesario explicitar el modelo de razón pública que diseña Rawls en su Liberalismo Político, de forma que la democracia sea la expresión de la razón que se aplica a todos, logrando un perfecto equilibrio entre el principio de legitimidad liberal y el principio de legitimidad democrática ${ }^{7}$.

\footnotetext{
${ }^{7}$ Sobre este tema de cómo equilibrar el principio liberal y el principio democrático desde la perspectiva contractualista es interesante el artículo de Peter de Marneffe (1994). Véase también J. Habermas (1992 y 1999); J. Cohen (1991 y1993).
} 
El punto de partida, es intentar responder a la siguiente pregunta: ¿Cuándo pueden los ciudadanos, a través de su voto, ejercer propiamente su poder político coercitivo unos respecto de otros cuando las cuestiones fundamentales están en juego?

Para Rawls,

«.... nuestro ejercicio del poder político es propio y consiguientemente justificable sólo si se realiza de acuerdo con una constitución, la aceptación de cuyas esencias pueda razonablemente presumirse de todos los ciudadanos a la luz de principios ideales admisibles para ellos como razonables y racionales. Éste es el principio liberal de legitimidad ${ }^{8}$.

Mas para comprender esta respuesta es necesario analizar, previamente, la noción de razón pública, y cómo se delimita el dominio de lo político y lo que puede o no servir de razones justificativas en ese ámbito.

Comencemos por señalar que la razón es vista como la capacidad de un ser para actuar por razones, esta capacidad se encuentra tanto en los individuos como en muchos cuerpos artificiales (clubes, iglesias, corporaciones privadas y públicas, gobiernos, etc.). Las razones son, normalmente, representaciones de un sujeto acerca de cómo es o debería ser alguna parte del mundo. Esta capacidad de actuar por razones va unida naturalmente en el agente racional a una capacidad normativa que le permite determinar y adecuar sus acciones y sus creencias (D. Gauthier, 1993 y 1995).

En este sentido la sociedad política, en realidad cualquier agente razonable y racional, ya se trate de un individuo, una familia, una asociación, etc., tiene un modo determinado de fijar sus fines en un orden de prioridades y de tomar sus decisiones de acuerdo con ese orden y de dar razones de la mismas en base a sus visiones del mundo. La forma como una sociedad política hace eso es su razón. Pero no todas las razones son razones públicas.

La razón pública es la razón de un pueblo democrático. Es la razón de quienes comparten una posición de igual ciudadanía. Su objeto es el bien público: aquello que la concepción política de justicia exige a la estructura institucional básica de la sociedad y a los propósitos y fines que las instituciones han de servir (J. Rawls, 1993, pp. 213 ss.).

La razón pública es la razón de ciudadanos iguales, que como cuerpo colectivo ejercen un poder político determinante y coercitivo unos respecto de otros aprobando leyes y mejorando la constitución.

Se trata de una concepción ideal de ciudadanía para un régimen constitucional democrático que se limita a presentar cómo podrían ser las cosas si la gente fuera tal y como una sociedad justa y bien ordenada les incitaría a ser. Describe lo que es posible, lo que puede ocurrir, aunque quizás nunca ocurra, sin dejar por ello de ser fundamental.

8 J. Rawls, 1993, p. 217, véase también pp. 137 y ss.) (la traducción es mía). 
La razón pública impone restricciones, límites, pero éstos no rigen para todas las cuestiones políticas, sino sólo para aquellas que impliquen o se refieran a las esencia constitucionales y cuestiones básicas de justicia ${ }^{9}$. Tampoco rigen para los ciudadanos en todos los ámbitos, sino sólo cuando se comprometen en la defensa de una determinada política en el foro público, por ejemplo: los miembros de los partidos políticos y los candidatos en sus campañas electorales, o cuando deben votar en las elecciones sobre temas en los que están en juego las esencias constitucionales o cuestiones básicas de justicia. También rige para los funcionarios en los foros públicoestatales: legislativo, ejecutivo y poder judicial. Sobre todo rige para el Tribunal Supremo en una democracia constitucional con revisión judicial, pues éste se convierte en el paradigma de la razón pública.

Todo ello nos lleva a plantearnos la relación entre la razón pública y el ideal de ciudadanía democrática. Que no es otra cosa, nos dirá Rawls (1993, pp. $216 \mathrm{ss}$.), que intentar responder a las preguntas: ¿Por qué deberían los ciudadanos respetar los límites de la razón pública cuando discuten y votan sobre las cuestiones políticas fundamentales? ¿A la luz de qué principios e ideales debemos ejercer el poder político si su ejercicio ha de justificarse frente a los demás en tanto que ciudadanos libres e iguales?

La respuesta rawlsiana se basa fundamentalmente en el principio de legitimidad liberal que está ligado a los rasgos especiales que caracterizan la relación política entre ciudadanos y al hecho histórico de la existencia de un pluralismo de doctrinas razonables. En definitiva, en su idea de razón públi$c a$, que tal como él la entiende,

... pertenece a la concepción de una democracia constitucional bien ordenada. La forma y el contenido de la razón pública [...] corresponde a la idea misma de democracia. Pues una de las características fundamentales de la democracia es el hecho del pluralismo razonable, el hecho de que una pluralidad de doctrinas generales razonables en conflicto (religiosas, filosóficas y morales) es el resultado normal de su cultura de instituciones libres. Los ciudadanos advierten que no pueden alcanzar acuerdos e incluso aproximarse al mutuo entendimiento si se apoyan en sus irreconciliables doctrinas generales. [...] Propongo, pues, que en el ámbito de la razón pública, las doctrinas generales sobre lo verdadero o lo justo sean sustituidas por una idea de lo políticamente razonable que se dirija a ciudadanos como ciudadanos ${ }^{10}$.

${ }^{9}$ Para Rawls las esencias constitucionales son de dos tipos:

a) Los principios fundamentales que definen la estructura general del Estado y el proceso político; los poderes legislativo, ejecutivo y judicial, y el alcance de la regla de la mayoría.

b) La igualdad de derechos y libertades ciudadanas básicas que las mayorías legislativas han de respetar, tales como el derecho al voto y la participación política y las tutelas proporcionadas por el imperio de la ley (J. Rawls, 1993, pp. 227-230) (la traducción es mía).

Sobre el papel central que los conceptos englobados en las esencias constitucionales del segundo tipo tienen en el pensamiento de Rawls desde sus comienzos véase M. ${ }^{a}$ Pilar González Altable (1993).

\footnotetext{
10 J. Rawls (2001, p. 155).
} 
Resulta esencial, por tanto, que la idea de razón pública no critique ni ataque a ninguna doctrina global, religiosa o no religiosa, salvo si tal doctrina es incompatible con los fundamentos de la razón pública y de la sociedad democrática. La exigencia básica para Rawls es

... que una doctrina razonable acepte la democracia constitucional y su complemento el Derecho legítimo (J. Rawls, 2001, p. 156).

La idea de razón pública especifica, al nivel más profundo, los valores morales y políticos básicos que determinan las relaciones de un gobierno democrático con sus ciudadanos y de éstos entre sí. Por tanto, quienes rechazan la democracia constitucional con su criterio de reciprocidad, rechazarán obviamente la idea misma de la razón pública. El celo que entraña la verdad absoluta en política es incompatible con una idea de razón pública que forma parte de la ciudadanía democrática (J. Rawls, 2001, p. 157).

El ideal de ciudadanía exige, por tanto, que el ejercicio del poder político debe ser legítimo y ello junto con el criterio de reciprocidad y el ideal de razón pública impone un deber moral, no legal: el deber de civilidad.

Ese deber implica una disposición a escuchar a los demás, así como ecuanimidad a la hora de decidir cuándo sería razonable acomodarse a los punto de vista de los demás. Su práctica posibilita el poderse explicar unos a otros, respecto de las cuestiones fundamentales, que las políticas y los principios por los que abogan pueden justificarse en los valores políticos de la razón pública.

Intentar satisfacer esa condición es una de las tareas que el ideal de la política democrática nos plantea. Pues aprender a conducirnos como ciudadanos democráticos incluye la comprehensión de un ideal de la razón pública.

Parte de ese ideal son los valores políticos realizados por un régimen constitucional bien ordenado. Estos valores son muy elevados y por ello mismo muy difíciles de eludir. Los ideales que esos valores expresan no pueden ser abandonados a la ligera.

Los valores políticos (los derechos y libertades fundamentales, la igualdad, etc.) y el deber de civilidad se nos presentan como la realización del ideal de los ciudadanos que se gobiernan a sí mismos a través de formas tales que cada uno pueda razonablemente esperar que resulten aceptables para todos.

Al mismo tiempo ese ideal resulta robustecido por las doctrinas comprehensivas que las personas razonables sostienen.

\footnotetext{
Sobre este punto es interesante el análisis de J. Cohen sobre la democracia deliberativa, cuando plantea el problema del pluralismo razonable y la legitimidad democrática, señalando cómo la argumentación pública es esencial para legitimar la toma de decisiones colectivas, legitimidad que no sólo depende de seguir los procedimientos correctos, sino que también tiene que atender al contenido, que debe ser, como también señala Rawls, valores políticos.
} 
De modo que cuando la concepción política se funda en un consenso superpuesto de doctrinas comprehensivas razonables la paradoja de la razón pública desaparece.

... los ciudadanos sostienen el ideal de la razón pública, no como producto de un compromiso político, como si de un modus vivendi se tratara, sino desde sus propias doctrinas razonables ${ }^{11}$.

Ello le lleva a Rawls a rechazar en este contexto, tanto el punto de vista de aquellos que defienden que los individuos a la hora de votar deben guiarse solamente por sus preferencias, como el de aquellos que mantienen que deben hacerlo en base a lo que consideran la verdad global (J. Rawls, 1993, p. 219), porque ninguno cumple con el deber de civilidad ni aceptan el ideal de razón pública.

La razón pública con su deber de civilidad adopta, para Rawls, en lo concerniente a las cuestiones fundamentales, un punto de vista con ciertas reminiscencias del contrato social rousseauniano: el voto, como expresión ideal de nuestra opinión sobre qué alternativa promueve mejor el bien común.

En suma, lo que plantea el liberalismo político es que cualquiera que sea el modo en que se decida sobre las cuestiones fundamentales (derechos, libertades y cuestiones básicas de justicia) el contenido de una concepción política de justicia incluye los valores de la razón pública de acuerdo con los cuales deben juzgarse dichas cuestiones.

Pues sólo de esa forma y aceptando que la política en una sociedad democrática nunca puede guiarse por lo que consideramos la verdad global, podemos realizar el ideal expresado por el principio de legitimidad liberal: «vivir políticamente con otros a la luz de razones que pueda esperarse razonablemente que todos aceptarán» (J. Rawls, 1993, VI). Todo ello supone la incorporación de la tolerancia a la filosofía misma.

La razón pública lo único que exige es que los ciudadanos sean capaces de explicar su voto unos a otros en términos de un balance razonable de valores políticos públicos. Entendiendo todos y cada uno de ellos que la pluralidad de doctrinas comprehensivas razonables que sostienen son concebidas por ellos mismos, como un fundamento ulterior, y a menudo trascendente, de esos valores.

Es verdad, dirá Rawls, que el balance de los valores políticos que hace cada ciudadano tiene que ser razonable y parecer razonable a los demás, pero no todos los balances razonables son iguales. Las únicas doctrinas comprehensivas que chocan con la razón pública son las que resultan incompatibles con un balance razonable de los valores políticos.

Los límites de la razón pública no son los límites de la ley o el Derecho, sino los límites que respetamos cuando respetamos un ideal:

$"$ J. Rawls, 1993, p. 218; véase también 1987, 1989 (la traducción es mía). 
... el ideal de ciudadanos democráticos que tratan de conducir sus asuntos políticos en términos avalados por valores públicos, de los que pueden razonablemente esperarse que serán aceptados por todos (J. Rawls, 1993, p. 253).

Los límites de la razón pública son los límites que vienen impuestos por la concepción política de justicia.

\section{Conclusión}

De esta forma, en el Liberalismo Político se da una clara coimplicación entre justicia y democracia. La teoría de la justicia se nos presenta como el paradigma legitimador tanto de la esfera de la legalidad como de la esfera política.

Ello sigue marcando, a mi modo de ver, las diferencias entre el modelo rawlsiano y el habermasiano de la democracia deliberativa ${ }^{12}$. Aunque cada vez más, ambos paradigmas tienden a coincidir, como muy bien ha señalado F. Vallespín (1995), en una misma apuesta filosófico-política: abrir espacios para que cada una de estas dimensiones (la de la moralidad y la de la eticidad) encuentren una satisfacción plena dentro de un esquema de cooperación social entre ciudadanos libres e iguales.

Lo que es evidente es que la concepción presentada de la razón pública está comprometida, sobre todo, con delimitar un espacio que no puede estar sometido a intereses, ya sean estratégicos o incluso deliberativos, porque está garantizado por la concepción política de justicia, aceptada por todos, como ese mínimo con pretensiones de universalidad por ahistórico, no en el sentido de que no tenga un origen histórico y no haya sido el resultado de largas luchas, sino en cuanto producto del ejercicio de la razón humana libre. Un mínimo que ejemplifica los valores esenciales presumidos en el ideal democrático que subyace a un régimen democrático constitucional.

El ideal rawlsiano de la razón pública establece, en definitiva, los límites dentro de los cuales debe transcurrir la deliberación pública en el foro público, donde la base de la argumentación, sobre cuestiones fundamentales, deben ser razones correctas si queremos respetar el ideal de ciudadanía democrática ${ }^{13}$.

La política deliberativa implica, así, un intercambio razonado entre personas que se reconocen unos a otros como iguales, en autoridad y dignidad, que se dirigen a responder cuestiones sobre la ordenación pública.

\footnotetext{
${ }_{12}$ Pues para Habermas una interpretación teorético-discursiva insiste en el hecho de que la formación democrática de la voluntad no extrae de antemano su fuerza legitimadora de la convergencia de opiniones éticas sustantivas, sino de los supuestos y procedimientos comunicativos que permiten que los mejores argumentos afloren en el proceso de deliberación (J. Habermas, 1992).

${ }^{13}$ Sobre este punto es interesante el análisis de D. Gauthier (1993); véase también M. ${ }^{a}$ Pilar González (2001).
} 
En este sentido, Rawls entraría a formar parte de los pensadores que J. Gray (2001) denomina liberales legalistas que intentan superar el conflicto entre formas de vida diferentes a través del ideal de justicia y los derechos. Un ideal de justicia que nos lleva a legitimar el Derecho (law) como un estándar de razón pública predominante sobre el ejercicio del juicio privado y dirigiendo a las personas hacia su mutua ventaja y el reconocimiento de que son iguales en autoridad y dignidad, pero teniendo en cuenta, como nos señala D. Gauthier (1993), «que esta recta razón, que es el Derecho, no es ciertamente recta, nada más que por hacerla así al apropiarnos de ella y someternos voluntariamente a su sujeción».

\section{BIBLIOGRAFÍA}

ÁGUILA, Rafael del (1995): «El centauro transmoderno: Liberalismo y democracia en la democracia liberal», en F. VALleSPín (ed.), Historia de la teoría política, vol. 6, Madrid, Alianza Editorial, pp. 549-643.

CoHEN, J. (1991): «Deliberation and Democratic Legitimacy», en A. HAMLIN y PHILIP PETTrT (eds.), The Good Polity, Basil Blackwell.

- (1993): «Moral Pluralism and Political Consensus», en D. CoopP y J. HAMPTON (eds.), The Idea of Democracy, Cambridge, Cambridge University Press.

- (2001): «Democracia y libertad», en Jon ELSTER (comp.), La democracia deliberativa, Barcelona, Gedisa.

DíAZ, Elías (2002): «La universalización de la democracia: Los hechos y los derechos», en Anales de la Cátedra Francisco Suárez, núm. 36, pp. 45-62.

FreEMAN, S. (1990): «Reason and Agreement in Social Contract Views», en Philosophy and Public Affairs, núm. 2, pp. 122-157.

GAUTHIER, D. (1993): «Constituting Democracy», en D. Coopp y J. HAMPTON (eds.), The Idea of Democracy, Cambridge, Cambridge University Press.

- (1995): «Public Reason», en Social Philosophy and Policy, vol. 12, núm. 1, pp. 19-42.

GRAY, John (2001): Las dos caras del liberalismo, Barcelona, Paidós.

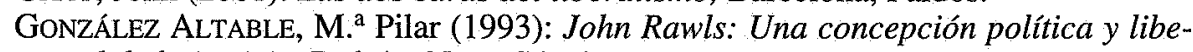
ral de la justicia, Padrón, Novo Século.

- (2001): «Contrato moral-contrato político: David Paul Gauthier», en Ramón MaIz (comp.), Teorías políticas contemporáneas, Valencia, Tirant lo Blanch.

Gutmann, A. (1995): «The Challenge of Multiculturalism in Political Ethics», Philosophy and Public Affairs, núm. 3, pp. 171-207.

- (ed.) (1994): Multiculturalism. Examining The Politics of Recognition, Princeton University Press.

HABERMAS, J. (1992): Facktizitat un Geltung. Berträge zur Diskursthorie des Rechts und des demokratischen Rechtsstaats, Frankfort, Suhrkamp (trad. cast.: Facticidad y Validez, 3. ${ }^{a}$ ed., Madrid, Trotta, 2001. Se citará por la edición castellana).

- (1994): «Struggles for Recognition in Constitutional States», en A. GuTMANN (ed.), Multiculturalism. Examining The Politics of Recognition, Princeton University Press, pp. 107-149. 
- (1999): «Tres modelos normativos de democracia», en La inclusión del otro. Estudios de teoría política, Barcelona, Paidós, pp. 231-247.

LUCAS, Javier de (1994a): «¿Elogio de Babel? Sobre las dificultades del derecho frente al proyecto intercultural», en Anales de la Cátedra Francisco Suárez, núm. 31, pp. 15-41.

- (1994b): Las fronteras y los derechos, Madrid, Temas de Hoy.

MARNEFFE, P. (1994): «Contractualism, Liberty, and Democracy», en Ethics, vol. 104 núm. 4 , pp. 764-784.

RAwLS, J. (1972), Theory of Justice, Oxford, Blakwell (trad. cast.: Teoría de la justicia, México, FCE, 1979).

- (1985): «Justice as Fairness: Political not Metaphysical», en Philosophy and Public Affairs, vol. 14, núm. 3, pp. 223-251.

- (1987): «The Idea of an Overlapping Consensus», en Oxford Journal of Legal Studies, vol. 7, núm. 1, pp. 1-26.

- (1989): «The Domain of the Political and Overlapping Consensus», en New York University Law Review, núm. 2, pp. 233-255.

- (1993) Political Liberalism, New York, Columbia University Press (trad. cast.: Liberalismo Político, Barcelona, Critica, 1996).

- (1995): «Reply to Habermas», en The Journal of Philosophy, vol. XCII, núm. 3 (trad. cast.: Fernando Vallespín, Jürgen Habermas/John Rawls. Debate sobre el liberalismo político, Barcelona, Paidós, 1998).

- (1996): Political Liberalism. With a New Introduction and the «Reply to Habermas», Nueva York, Columbia University Press, edición en paperback.

- (1999): The Law of Peoples. With «The Idea of Public Reason Revisited», Cambridge, Harvard University Press.

- (2001a): El derecho de gentes y «una revisión de la idea de razón pública», Barcelona, Paidós.

- (2001b): Justice as Fairness. A Restatement, Cambridge, Harvard University Press (trad. cast.: Justicia como equidad. Una reformulación, Barcelona, Paidós, 2002).

SARTORI, Giovanni (2001): La sociedad multiétnica. Pluralismo, multiculturalismo y extranjeros, Madrid, Taurus.

SEBRELI, Juan José (1992): El asedio a la modernidad, Barcelona, Ariel.

SHEFFLeR, S. (1994): «The Appeal of Political Liberalism», Ethics, vol. 105, núm. 1, pp. 4-23.

THIEBAUT, Carlos (1994): «Democracia y diferencia: un aspecto del debate sobre el multiculturalismo», en Anales de la Cátedra Francisco Suárez, núm. 31, pp. 41-61.

Touraine, A. (1994): ¿Qué es la democracia?, Madrid, Temas de Hoy.

- (1995): ¿Qué es una sociedad multicultural», en Claves de la Razón Práctica, núm. 56, pp. 14-25.

VALLESPÍN, F. (1995): «Diálogo entre gigantes. Rawls y Habermas», en Claves de la Razón Práctica, núm. 55, pp. 48-55.

- (1998): «Introducción», en Jürgen Habermas/John Rawls. Debate sobre el liberalismo político, Barcelona, Paidós. 